This manuscript is a preprint and has been submitted for publication in Environmental

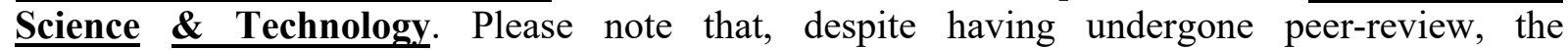
manuscript has yet to be formally accepted for publication. Subsequent versions of this manuscript may have slightly different content. If accepted, the final version of this manuscript will be available via the 'Peer-reviewed Publication DOI' link on the right-hand side of this webpage. Please feel free to contact any of the authors; we welcome feedback. 


\title{
On the impact of Urbanisation on $\mathrm{CO}_{2}$ Emissions
}

\author{
Muhammad Luqman ${ }^{1 *}$, Peter J. Rayner ${ }^{1,2}$, and Kevin R. Gurney ${ }^{3}$ \\ ${ }^{1}$ School of Geography, Earth and Atmospheric Sciences, University \\ of Melbourne, Australia \\ ${ }^{2}$ Melbourne Climate Futures/Climate and Energy College, \\ University of Melbourne, Australia \\ ${ }^{3}$ School of Informatics, Computing and Cyber Systems, Northern \\ Arizona University, United States of America \\ *corresponding author email: mluqman@student.unimelb.edu.au
}

2021-11-01

\begin{abstract}
We use a globally consistent, time-resolved data set of $\mathrm{CO}_{2}$ emission proxies to quantify urban $\mathrm{CO}_{2}$ emissions in 91 cities. We decompose emission trends into contributions from changes in urban extent, population density and per capita emissions. We find that urban $\mathrm{CO}_{2}$ emissions are increasing everywhere but that the dominant contributors differ according to development level. A cluster analysis of factors shows that developing countries were dominated by cities with rapid area and per capita $\mathrm{CO}_{2}$ emissions increases. Cities in the developed world, by contrast, show slow area and per capita $\mathrm{CO}_{2}$ emissions growth. China is an important intermediate case with rapid urban area growth combined with slower per capita $\mathrm{CO}_{2}$ emissions growth. For many developed countries, urban per capita emissions are often lower than their national average suggesting that urbanisation may reduce overall emissions. However trends in per capita urban emissions are higher than their national equivalent almost everywhere suggesting that urbanisation will become a more serious problem in future. An important exception is China whose per capita urban emissions are growing more slowly than the national value. We also see a negative correlation between trends in population density and per capita $\mathrm{CO}_{2}$ emissions, highlighting a strong role for densification as a tool to reduce $\mathrm{CO}_{2}$ emissions.
\end{abstract}

Keywords: Urban GHG emissions, Remote Sensing, Urban GHG trends, GHG emissions contributors, Kaya identity 


\section{Introduction}

Cities are responsible for close to $70 \%$ of global $\mathrm{CO}_{2}$ emissions associated with energy consumption [Seto et al., 2014]. In North America the proportion reaches $80 \%$ depending upon the definition of emissions scope and urban boundary [Jones and Kammen, 2014; Gurney et al., 2020]. Furthermore, cities could add over 2 billion people this century with global urban area tripling by 2030 [Seto et al., 2012; Nations, 2018]. While concern mounts over the potential "lockin" of high-emitting infrastructure, many cities also have taken leadership on greenhouse gas mitigation, pledging ambitious reduction targets [Seto et al., 2016; C40 et al., 2019]. Quantifying trends in urban $\mathrm{CO}_{2}$ emissions is critical to understand near-term urban emission trajectories. Identifying major contributions to these trends will help expose the factors driving emissions over the longer term. These drivers are points of mitigation leverage, a goal of several urban alliances such as the Global Covenant of Mayors or the C40 Cities Alliance [Wang et al., 2012].

Given the rate of urbanisation, it is important to establish whether, on average, urbanisation contributes to increased national/global $\mathrm{CO}_{2}$ emissions. This has been a source of considerable debate with the consensus that developing cities are generally wealthier and more energy intensive than the rural areas from which they draw their population. Thus, urban-dwellers will consume more energy when compared to rural lifestyles such that urbanisation per se, drives increased $\mathrm{CO}_{2}$ emissions [Little et al., 2016]. A countervaling view is that, beyond some stage in its development, economic growth in cities comes from low-emissions service industries so that urbanisation will be a decreasing or even negative contributor to national/global $\mathrm{CO}_{2}$ emission trends [Uchiyama, 2016]. This is a version of the Environmental Kuznets Curve (EKC) [Grossman and Krueger, 1991]. The more general statement of the EKC, that economic growth will first worsen but then improve environmental outcomes has been both theoretically and empirically controversial [Stern, 2017].

Given the rates of urban population growth there is little doubt that urban emissions are rising. If we define urbanisation as an increase in urban versus non-urban populations it is still possible that urbanisation may reduce emissions. The determining factor is the difference between urban and non-urban per capita emissions and the trend in this difference. Let us define the Urbanisation Kuznets Curve (UKC) by analogy with the EKC to say that, above some level of economic development, urbanisation per se switches from a positive to a negative contributor of emissions.

Empirical evidence for the UKC is limited because we need consistent information for enough cities over long enough periods to ascertain trends. During the last three decades a lot of local work has examined the relationship between urbanisation and carbon emissions: Malaysia [Shahbaz et al., 2016], Turkey [Katircioğlu and Katircioğlu, 2018], African region [Al-Mulali et al., 2013; Salahuddin et al., 2019], developed countries [Liddle and Lung, 2010], developing countries [Martinez-Zarzoso and Maruotti, 2011; Sadorsky, 2014], Europe [Khoshnevis Yazdi and Shakouri, 2018], U.S. [Dogan and Turkekul, 2016], Japan 
[Ouyang and Lin, 2017], U.K. [Baiocchi and Minx, 2010]. Other studies have addressed different time scales: [Bares et al., 2019; Dhakal, 2009; Duren and Miller, 2012] for long-term emissions, [Patarasuk et al., 2016; Sargent et al., 2018] for shorter time scales and [Turnbull et al., 2015] on seasonal scales.

The variability of previous results may reflect reality but equally may reflect the fact that these studies address different development stages, different regions, different time spans, different spatio-temporal resolutions, different scales and techniques of measurements. To probe this question we must separate the contributions of population growth and per capita $\mathrm{CO}_{2}$ emissions trends from total $\mathrm{CO}_{2}$ emissions growth. Such analyses require time series of urban extent and $\mathrm{CO}_{2}$ emissions with global coverage and enough duration to establish trends. No direct data set allows this but there are now reliable, remotely-sensed proxies of urban energy consumption or $\mathrm{CO}_{2}$ emissions which meet these criteria. By combining these with measures of urban extent and some underlying emissions contributors we can generate a global picture of the interaction of urbanisation and $\mathrm{CO}_{2}$ emissions.

The other reason to monitor urban emissions directly is more practical. The United Nations Framework Convention on Climate Change [Agreement, 2015] suggests monitoring the spatiotemporal variations of GHG emissions to inform international climate change policy [Figueres et al., 2018; Raupach et al., 2007]. Atmospheric concentration measurements combined with on-ground information is emerging as the means to best achieve the combination of accurate emissions tracking and detailed source characterization of emissions in urban areas [Gurney et al., 2015; Lauvaux et al., 2020; Gurney et al., 2021].

The structure of this paper is as follows: Section 2 describes the analytical method, a modified form of the Kaya identity, and the data sources used in our analysis. Section 3 describes the resulting trends in these emission contributors, a cluster analysis to place the trends in a regional context, and placement of urban emissions within the national context to demonstrate the potential impact cities may have on future national trends. Section 4 comments on the implications and caveats of the results while Section 5 summarises our major findings.

\section{Methods}

Our task is to calculate trends in fossil fuel emissions for major cities, decompose these into their dominant contributors and investigate possible patterns in these contributors. Our chosen contributors are population, area and per capita emissions. Our analysis requires data for urban extent, fossil fuel $\mathrm{CO} 2$ emissions and population. Urban extent is generated from the Built-up, Nightlight and Travel Time for Urban Size (BUNTUS) algorithm of Luqman et al. [2019]. This algorithm defines a metric based on land cover classification, nightlight intensity and travel time to an urban centroid. All contiguous 30 arc second pixels scoring above a threshold are included and the algorithm accounts for non-urban "islands" such as large parks or open space inside cities. We com- 


\begin{tabular}{|l|l|l|} 
Sr. No. & City & Country \\
\hline 1 & Abidjan & Cote d'Ivoire \\
2 & Accra & Ghana \\
3 & Alexandria & Egypt \\
4 & Bogota & Colombia \\
5 & Kinshasa & Dem. Republic Congo \\
6 & Kuwait & Kuwait \\
7 & Lagos & Nigeria \\
8 & New York & United States \\
9 & Onitsha & Nigeria \\
10 & Quanzhou & China \\
11 & Singapore & Singapore \\
12 & Xiamen & China \\
\hline
\end{tabular}

Table 1: List of excluded cities

menced our analysis with 91 cities chosen mainly by population [Demographia, 2015]. The 91 cities span 39 countries with nineteen in China, twelve in the United States and nine in India. All other countries represented have three or fewer cities. Our study period covers 2000-2018, the longest period for which all our required data sets exist.

Some large cities are excluded from the study. There are two reasons for this. Firstly, the necessary imagery may not exist across enough of our study period. The usual gap is the LandSat imagery necessary to characterise the urban boundary. The second is that some cities exist as parts of such large agglomerations that their boundaries cannot be defined by physical data. The clearest example is New York City which forms part of a larger agglomeration on the East Coast of the U.S. The total list of excluded cities is listed in Table 1. There is a problem of classification for some cities. As noted by Luqman et al. [2019], a common trajectory for growing cities is that two regions defined as urban by BUNTUS fuse to a single region. This obviously changes area and consequently total emissions suddenly, complicating trend analysis. Where this occurs we carry out the analysis for the whole period and include any city defined within the largest boundary of our chosen city (usually 2018). For example, Beijing commences with 14 cities in 1998 and finishes with one in 2018. The name we assign to the final city is its name in 2018.

Gridded population estimates come from the LandScan product [Bhaduri et al., 2007]. LandScan is a global population database depicting an ambient (24-hour average) population distribution. The LandScan methodology disaggregates subnational census information through a suite of dynamically adaptable algorithms using spatial data, imagery-derived spatial products, and manual corrections. LandScan exploits spatial data and imagery analysis technologies in a multi-variable asymmetric modeling approach [Dobson et al., 2000]. LandScan data represents an average, or ambient, population that integrates diurnal movements and collective travel habits into a single measure [Dobson 
et al., 2000]. This is different from purely residential population maps but is better suited for comparison with emissions which include both residential and nonresidential activities of the target population.

$\mathrm{CO}_{2}$ emissions are taken from The Open-Data Inventory for Anthropogenic Carbon dioxide (ODIAC) [Oda et al., 2018]. The ODIAC is a global high resolution $(1 \mathrm{~km} \times 1 \mathrm{~km})$ fossil fuel $\mathrm{CO}_{2}$ emission data product [Oda et al., 2018; Oda and Maksyutov, 2011]. The ODIAC is based on spatial disaggregation of $\mathrm{CO}_{2}$ emission estimates made by the Carbon Dioxide Information Analysis Center (CDIAC) [Boden et al., 2017]. CDIAC emissions are estimated by fuel type (solid, gas, and liquid fuels, bunker fuel, and gas flares) plus cement production, rather than the emission sector that is often used for the national inventory compilation [Marland and Rotty, 1984]. The ODIAC spatial disaggregation is done in two steps. First, emissions from point sources (mainly power plants) are estimated and mapped using the power plant emission estimates and geolocation taken from a global power plant database. The rest of the emissions (country total minus point source emissions), which we refer to a non-point source emissions, are distributed using the spatial distribution of satellite-observed nightlight (NTL) intensities [Oda et al., 2018; Oda and Maksyutov, 2011]. Non-point source emissions are disaggregated to a $1 \mathrm{~km} \times 1$ $\mathrm{km}$ spatial resolution using Defense Meteorological Satellite Program (DMSP) calibrated radiance NTL data, with mitigated saturation effect, developed by NOAA's Earth Observation Group [Oda et al., 2010]. The calibrated radiance NTL data are a merged product of the regular DMSP NTL product and benefits from reduced gain observations [Ziskin et al., 2010]. Oda et al. [2010] show an improved spatial emissions distribution from the original publication by Oda and Maksyutov [2011] due to the use of the calibrated radiance data. We calculate emissions for each city in each year by summing all emissions from ODIAC for that year which lie within the polygon defined by BUNTUS.

\section{$2.1 \quad$ Kaya Identity}

We proceed by analogy with economics which frequently decomposes Gross Domestic Product (GDP) as a product of three terms

$$
\text { GDP }=\text { population } \times \text { participation } \times \text { productivity }
$$

Raupach et al. [2007] used a decomposition for national emissions. We write urban $\mathrm{CO}_{2}$ emissions using a modified KAYA identity Kaya et al. [1997] as a product of urban area, population density and per capita $\mathrm{CO}_{2}$ emissions.

$$
E=\text { Ape }
$$

where $E$ is the total $\mathrm{CO}_{2}$ emissions, $A$ the urban area, $p$ the population density (persons per unit area) and $e$ the per capita $\mathrm{CO}_{2}$ emissions (tons carbon per person). Following Raupach et al. [2007] we use a logarithmic transformation to decompose the proportional trend in $\mathrm{CO}_{2}$ emissions as

$$
\delta E=\delta A+\delta p+\delta e
$$


where $\delta$ represents a proportional trend defined by

$$
\delta x=\frac{d x / d t}{\bar{x}}
$$

and is usually expressed as a percentage per year. We stress that while expressions like Equation 2 are mathematical identities they are not statements of causality but may elucidate underlying causes. We apply the modified Kaya identity to our 91 cities,

\subsection{Cluster Analysis}

Cluster analysis is a method for objectively identifying groupings in multidimensional data. If each point is described by $\mathrm{N}$ parameters then these define its coordinate in an N-dimensional space. Clusters are defined so that the distance from every point in a cluster to its centroid (defined as the average of all the coordinates in the cluster) is less than that to the centroid of any other cluster. The number of clusters is set by the user and is generally chosen just short of the "break" in the curve expected when we move from delineating truly isolated clusters to partitioning randomly distributed points within clusters. The case for our analysis is shown in Figure 2. For our analysis we use the KMeans function from the python scikit-learn package [Arthur and Vassilvitskii, 2006].

\section{Results}

\subsection{Trends}

Figure 1 shows the emission trends for the 91 cities in our analysis. Overall we see rapid increases in urban $\mathrm{CO}_{2}$ emissions averaging 4.7\%/yr. These averages conceal considerable variability across cities with emission trends ranging from $-2.8 \% / y$ (Madrid Spain) to 11.0\%/y (Xi'an, China).

On average, the dominant contributor for $\mathrm{CO}_{2}$ emissions growth is the change in urban area, $(3.5 \% / \mathrm{yr})$. The change in population density contributes $-0.6 \% / y r$, indicating that cities continue to sprawl as they grow. The trend in per capita $\mathrm{CO}_{2}$ emissions makes a positive contribution (averaging $2.2 \% / \mathrm{yr}$ ).

There are also significant relationships among the trends. Table 2 shows the correlations among the contributors across the 91 cities. It is important to stress that these are not temporal correlations but represent the relationship between trends in the three contributor variables across the 91-city sample.

The correlation of the area trend with the other two contributors is to be expected: Cities that grow fast in areal extent, see declines in population density and increases in per capita $\mathrm{CO}_{2}$ emissions. More surprising is the correlation between the two intensive contributors, population density and per capita $\mathrm{CO}_{2}$ emissions. The relationship suggests that cities experiencing declines in population density, have increasing per capita $\mathrm{CO}_{2}$ emissions providing direct evidence of the impact of changing urban form on $\mathrm{CO}_{2}$ emissions. 


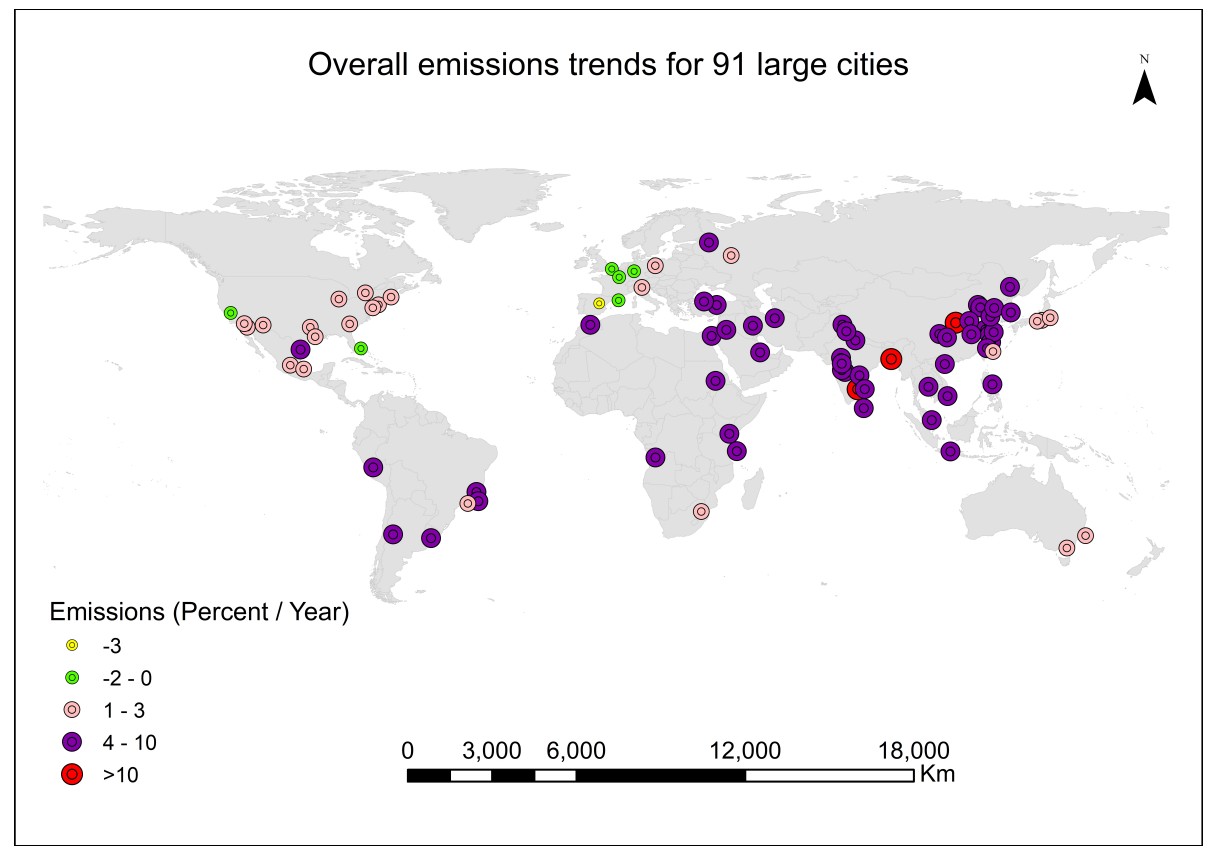

Figure 1: Overall emission trends for 91 large cities. Circles show the location of the chosen cities.

\begin{tabular}{rrrr} 
& $A$ & $P$ & $E$ \\
\hline$A$ & 1.00 & -0.52 & 0.37 \\
$P$ & -0.52 & 1.00 & -0.28 \\
$E$ & 0.37 & -0.28 & 1.00
\end{tabular}

Table 2: Correlations among proportional area trend $(A)$, proportional population density trend $(P)$ and proportional per capita $\mathrm{CO}_{2}$ emissions trend $(E)$

\subsection{Cluster Analysis}

While there is considerable spatial variability in trends and their contributors, some significant patterns emerge among classes of cities. We investigate these by performing a cluster analysis using the three contributors in Eq. 3. Figure 2 shows the average distance to centroids as a function of the number of clusters. Optimal choices for the number of clusters occur at inflections in this curve, with the segments between demonstrating partition of randomly distributed points. For our case the optimal choice is four.

Henceforth we focus on our choice of four clusters. Figure 3 shows the cluster assignment for each city while Table 3 shows the cluster characteristics.

The clusters can be classified according to their overall emission trends. This yields two high-growth clusters, one intermediate and one low-growth cluster. Cluster 1 shows a moderate positive area trend with large per capita emissions 


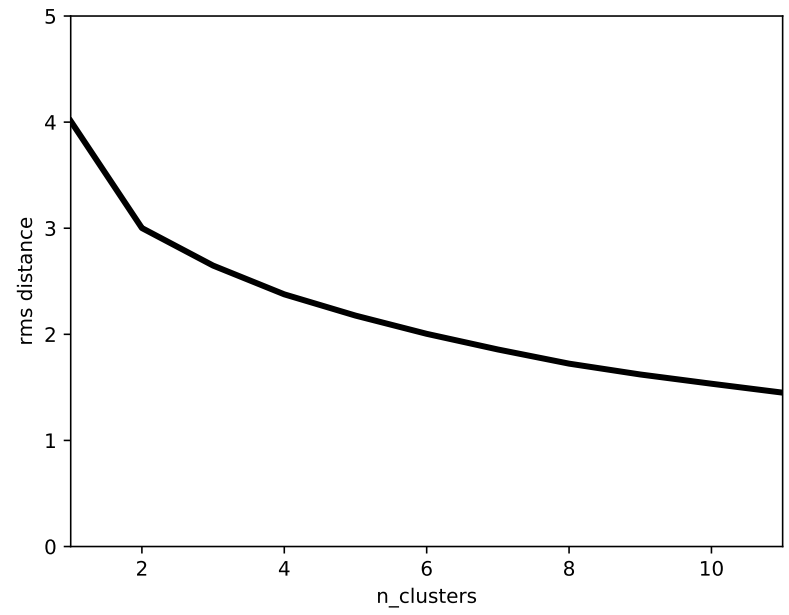

Figure 2: Mean distance to centroids as a function of the number of clusters

\begin{tabular}{lrrrrr} 
cluster & emission trend & area trend & pop density trend & percapita emissions trend & number-cities \\
\hline 1 & 7.9 & 3.5 & -0.8 & 5.9 & 20 \\
2 & 7.7 & 7.1 & -2.9 & 3.9 & 14 \\
3 & 5.1 & 2.9 & 0.6 & 2.1 & 30 \\
4 & 0.8 & 2.3 & -0.4 & -0.8 & 27 \\
\hline
\end{tabular}

Table 3: Characteristics of clusters defined as the coordinates of their centroids and the number of cities in the cluster. The full results for individual cities are listed in the supplementary data. We note that Equation 3 does not hold exactly for the cluster averages.

trend. It is dominated by cities in the developing world, mostly the Asian subcontinent. Cluster 2 exchanges these contributions with the area trend contributing more than the per capita emissions trend. It is dominated by Chinese cities. Clusters 3 and 4 show similar area trends but are differentiated by their per capita emissions trends. Cluster 3, with a positive per capita emissions trend, contains mostly cities throughout the developing world in addition to the two largest cities in Australia, Sydney and Melbourne. Cluster 4, with the lowest positive emissions trend, is the only cluster to show a negative per capita emissions trend. It consists almost entirely of cities in the developed world. The presence of Baghdad in this cluster suggests the role of conflict in reducing per capita emissions. 


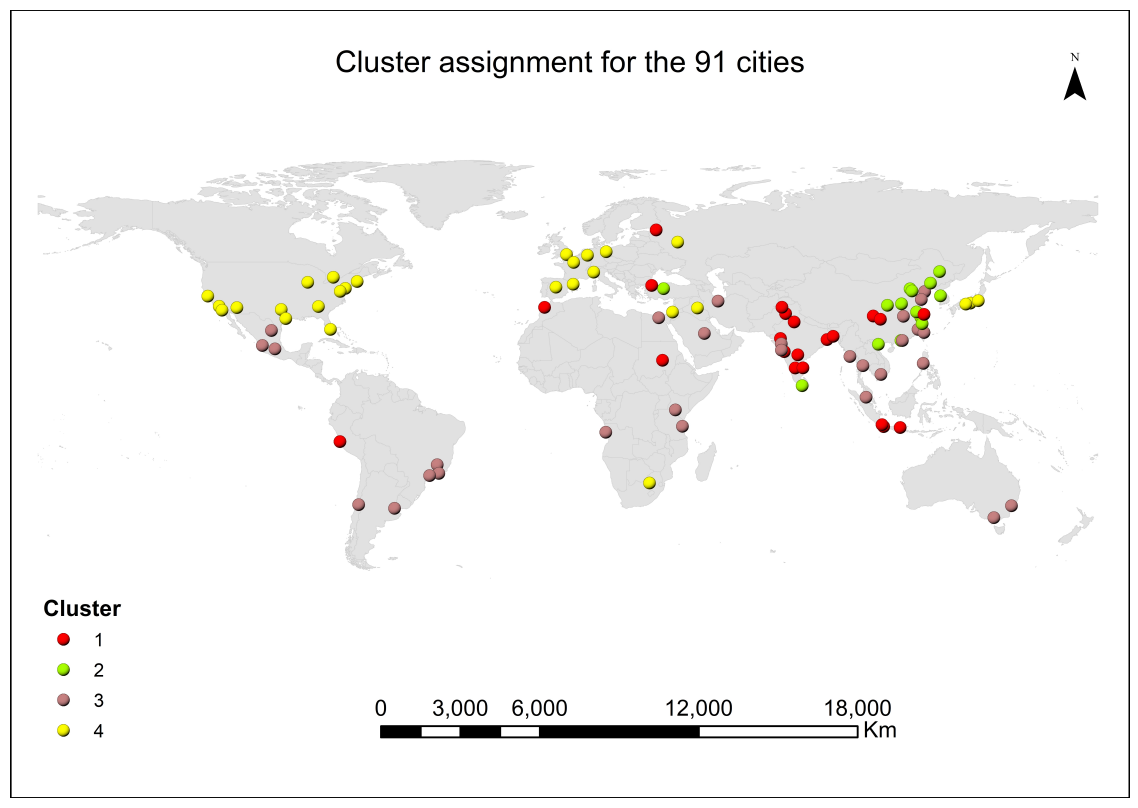

Figure 3: Cluster assignments for the 91 cities in the study, the cluster characteristics are described in Table 3

\subsection{National Emissions Impact of Urbanisation}

We define the rate of urbanisation as the trend in the proportion of the population living in cities. Let us define the national population as $P$, the urban fraction of the population as $c$, the urban per capita emissions as $u$ and the non-urban per capita emissions as $n$. We can write the national emissions as

$$
F=P[c u+(1-c) n]
$$

Differentiating yields

$$
\begin{aligned}
\frac{d F}{d t}= & \frac{d P}{d t}[c u+(1-c) n] \\
& +P(u-n) \frac{d c}{d t} \\
& +P\left[c \frac{d u}{d t}+(1-c) \frac{d n}{d t}\right]
\end{aligned}
$$

the role of urbanisation in trends in national emissions is the contribution of $\frac{d c}{d t}$ to $\frac{d F}{d t}$ i.e. $P(u-n)$. We also know that the national per capita emissions $e$ are given by

$$
e=c u+(1-c) n
$$


Some manipulation yields the coefficient of $\frac{d c}{d t}$ in Equation 6 as $P \frac{u-e}{1-c}$. thus, urbanisation contributes positively to the trend in national emissions if urban per capita emissions are higher than the national average and vice versa. Changes in the role of urbanisation hence depend on $\frac{d}{d t}(u-e)$, the trend in urban versus national per capita emissions. We can calculate the difference in per capita emissions for a reference year and the trend in this difference over our data set. We calculate the emissions for a reference year by fitting a linear regression to the per capita emissions and calculating the value of the resulting fit at the reference year (in this case 2010.5 representing the 2010 average). Figure 4 shows both these values for 39 countries containing cities in our data set.

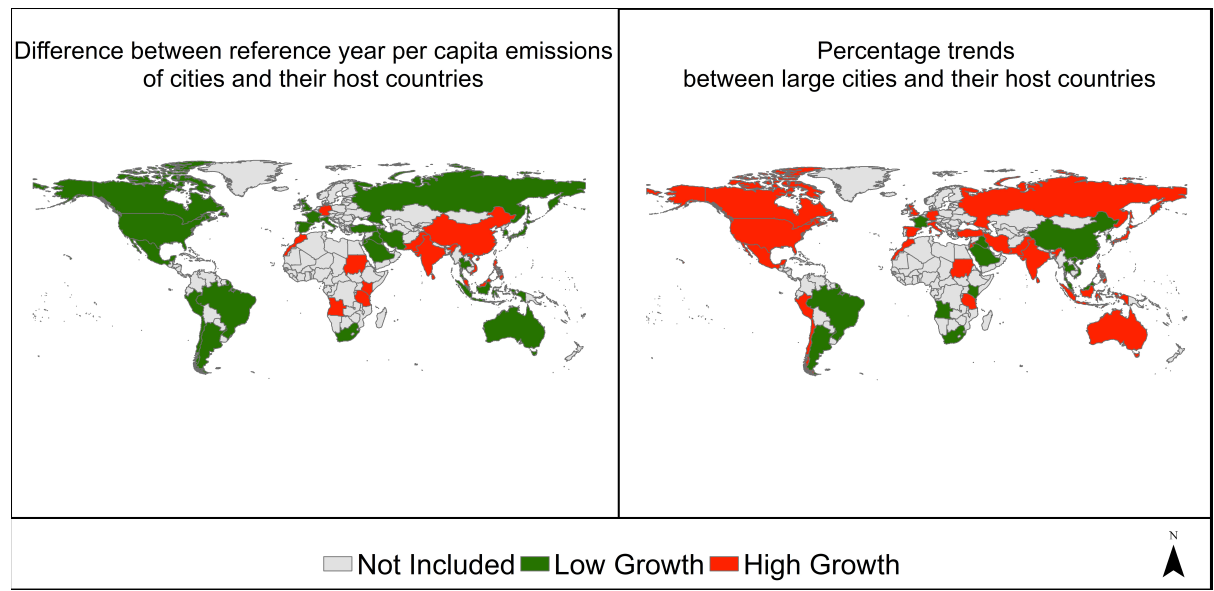

Figure 4: Difference between reference year per capita emissions (left) and percentage trend (trend divided by reference) (right) between large cities and their host countries. We average reference per capita emissions and trends for multiple cities in one country. The averaging is population-weighted. Egypt had too few points in its national emissions to allow calculation of trends and it is therefore excluded.

Figure 4 (left) shows that the current role of urbanisation is mixed. There is a tendency for developed countries to have urban per capita emissions lower than national emissions. This is by no means universal and several developing countries show the same behaviour. The case for trends in per capita emissions (right) is less equivocal. Here most countries show more rapid growth in urban than national emissions though again there are exceptions. There is little difference between developed and developing countries in this regard. One important exception is China whose 2010 urban per capita emissions are larger than the national value but with much slower growth. The results themselves do not shed light on whether this striking anomaly is a result of particularly emissions-efficient growth in China's cities or the result of explicit policy to move high-emissions industries away from cities, trading-off urban and non-urban $\mathrm{CO}_{2}$ emissions [Wang et al., 2013]. 


\section{Discussion}

There are several caveats to the analysis presented above. First, the spatial structure of $\mathrm{CO}_{2}$ emissions calculated here is deduced from the distribution of satellite-derived nighttime lights starting in the early 1990s [Elvidge et al., 1997; Doll et al., 2000; Elvidge et al., 2001]. These are used to "downscale" country level fossil fuel emissions provided by various national and international agencies [Raupach et al., 2010; Rayner et al., 2010; Asefi-Najafabady et al., 2014]. When considering urban $\mathrm{CO}_{2}$ emissions, the important quantity is the proportion of nighttime light irradiance arising from the city compared to the country as a whole. Trends in this proportion that arise from the different penetration rates of lighting technologies in urban and rural areas will contaminate our results. We expect these to introduce noise rather than bias since take-up of this technology is highly variable. This problem reaches its most acute with the reference emissions for 2010 .

There is also some ambiguity in the quantity represented by the ODIAC results displayed in Figure 4. The intensity of nightlights is a mixed indicator of emissions (scope 1) and energy consumption (scope 2). The comparisons with bottom-up inventories carried out by Asefi-Najafabady et al. [2014] suggest this is not a major limitation for this application. Furthermore, the role of urban development in overall emissions is also a mixed scope 1 and scope 2 problem so it is likely the nightlights distribution captures the relevant dynamics.

The results of this study have implications both for $\mathrm{CO}_{2}$ emissions projections and preferred modes of urban development. First we note the range of trends in per capita emissions. The per capita $\mathrm{CO}_{2}$ emissions trend is the largest single contributor to the urban $\mathrm{CO}_{2}$ emissions trend explaining, alone, $75 \%$ of the variance. Figure 4 shows that simple socioeconomic indicators such as per capita GDP do not explain the structure of per capita emissions trends. If there are discernible contributors of per capita $\mathrm{CO} 2$ emissions trends these might be valuable points of policy intervention to limit emissions growth. Possible candidates include urban form [Thompson et al., 2020] and economic specialisations.

The correlations among contributors of urban emissions also contain pointers for policy intervention. Table 2 shows that far from densifying, rapidly growing cities are generally "thinning". This is associated with a growth in per capita $\mathrm{CO}_{2}$ emissions. There is also a direct correlation between trends in population density and per capita emissions. Cities choosing a development path with greater population density are also minimising their growth in per capita $\mathrm{CO}_{2}$ emissions. The historical link between urban planning and carbon efficiency should motivate city managers to strengthen policies on urban density.

Figure 4 also carries an important lesson for studies of urban development and emissions. The left-hand side describes a snapshot in time. The snapshot suggests that per capita emissions decrease relative to national totals as cities develop. The trend analysis (right-hand side) suggests this is not the case. This highlights the importance of data sets that can probe the temporal and spatial aspects of urban development.

This work is an opening exploration of a potentially rich data set. While 
we have captured most of the world's largest cities, some are missing due to incomplete LandSat data or the impossibility of determining an urban boundary in a large agglomeration such as the U.S. East Coast. Nonetheless we should broaden the coverage of the data, in particular to include the mass of smaller cities which are also changing rapidly.

We stress that this analysis is descriptive rather than causal. Trends in multiple contributors may have common underlying drivers. Also we do not consider energy flows (either embodied or direct) between urban and non-urban regions. An important future task is to investigate underlying drivers of the relationships exhibited here. For example, how important is the trend in per capita GDP as an explanatory variable and can we learn anything about the carbon efficiency of the economies of different cities. This requires considerable care since many of the data sets attempting to spatially allocate economic activity also use nightlights as proxies, confounding the required independence of the explanatory variable.

\section{Conclusion}

We analysed trends of $\mathrm{CO}_{2}$ emissions for 91 of the world's largest cities using a new classification of urban boundaries overlaid on gridded fossil fuel $\mathrm{CO}_{2}$ emissions data. The average growth rate of $4.4 \% / y$ reflects rising $\mathrm{CO}_{2}$ per capita emissions globally and the growth in our chosen cities. With a modified Kaya identity as a framework, we decomposed urban $\mathrm{CO}_{2}$ emissions into three contributing variables: area, population density and per capita $\mathrm{CO}_{2}$ emissions. The trend in area contributes to $\mathrm{CO}_{2}$ emissions growth across almost all cities while the trend in per capita $\mathrm{CO}_{2}$ emissions makes a large contribution in most developing countries. Population density and per capita $\mathrm{CO}_{2}$ emissions trends correlate negatively, suggesting a relationship between changing urban form and per capita $\mathrm{CO}_{2}$ emissions. For our reference year of 2010 the per capita emissions in developed countries are generally lower than the national average while those in developing countries are generally higher. With the strong exception of China, emissions trends are generally larger for our chosen cities than the national averages suggesting that urbanisation will play an increasing role in driving national emissions and highlighting the importance of mitigation policies for cities.

\section{Acknowledgments}

We acknowledge Oak Ridge National Community (ORNL) for Landscan datasets, DMSP-OLS, and VIIRS products, and Google Earth. Muhammad Luqman is thankful to the University of Melbourne for a Melbourne Research Scholarship. 


\section{References}

Agreement, P., Unfccc, Adoption of the Paris Agreement, fccc/cp/2015/L, 9, 2015.

Al-Mulali, U., H. G. Fereidouni, J. Y. Lee, and C. N. B. C. Sab, Exploring the relationship between urbanization, energy consumption, and co2 emission in mena countries, Renewable and Sustainable Energy Reviews, 23, 107-112, 2013.

Arthur, D., and S. Vassilvitskii, k-means ++ : The advantages of careful seeding, Tech. rep., Stanford, 2006.

Asefi-Najafabady, S., P. J. Rayner, K. R. Gurney, A. McRobert, Y. Song, K. Coltin, J. Huang, C. Elvidge, and K. Baugh, A multiyear, global gridded fossil fuel co2 emission data product: Evaluation and analysis of results, Journal of Geophysical Research: Atmospheres, pp. n/a-n/a, 2014.

Baiocchi, G., and J. C. Minx, Understanding changes in the uk's co2 emissions: A global perspective, 2010 .

Bares, R., L. Mitchell, B. Fasoli, D. R. Bowling, D. Catharine, M. Garcia, B. Eng, J. Ehleringer, and J. C. Lin, The utah urban carbon dioxide (uucon) and uintah basin greenhouse gas networks: instrumentation, data, and measurement uncertainty, Earth System Science Data, 11, 1291-1308, 2019.

Bhaduri, B., E. Bright, P. Coleman, and M. L. Urban, Landscan usa: a highresolution geospatial and temporal modeling approach for population distribution and dynamics, GeoJournal, 69, 103-117, 2007.

Boden, T., R. Andres, and G. Marland, Global, regional, and national fossilfuel co2 emissions (1751-2014)(v. 2017), Tech. rep., Environmental System Science Data Infrastructure for a Virtual Ecosystem, 2017.

C40, Arup, and U. of Leeds, The Future of Urban Consumption in a 1.5C World, 2019.

Demographia, WORLD MEGACITIES Urban Areas with More than 10,000,000 Population, 2015.

Dhakal, S., Urban energy use and carbon emissions from cities in China and policy implications, Energy Policy, 37, 4208-4219, 2009.

Dobson, J. E., E. A. Bright, P. R. Coleman, R. C. Durfee, and B. A. Worley, Landscan: a global population database for estimating populations at risk, Photogrammetric engineering and remote sensing, 66, 849-857, 2000.

Dogan, E., and B. Turkekul, Co 2 emissions, real output, energy consumption, trade, urbanization and financial development: testing the ekc hypothesis for the usa, Environmental Science and Pollution Research, 23, 1203-1213, 2016. 
Doll, C. N. H., J.-P. Muller, and C. D. Elvidge, Night-time imagery as a tool for global mapping of socioeconomic parameters and greenhouse gas emissions, Ambio, 29, 157-162, 2000.

Duren, R. M., and C. E. Miller, Measuring the carbon emissions of megacities, Nature Climate Change, 2, 560-562, 2012, zSCC: 0000175.

Elvidge, C. D., K. E. Baugh, E. A. Kihn, H. W. Kroehl, and E. R. Davis, Mapping city lights with nighttime data from the dsmp operational linescan system, Photogrammetric Engineering and Remote Sensing, 63, 727-734, 1997.

Elvidge, C. D., M. L. Imhoff, K. E. Baugh, V. R. Hobson, I. Nelson, J. Safran, J. B. Dietz, and B. T. Tuttle, Night-time lights of the world: 1994-1995, Journal of Photogrammetry and Remote Sensing, 56, 81-99, 2001.

Figueres, C., C. Le Quéré, A. Mahindra, O. Bäte, G. Whiteman, G. Peters, and D. Guan, Emissions are still rising: ramp up the cuts, 2018.

Grossman, G. M., and A. B. Krueger, Environmental impacts of a north american free trade agreement, Tech. rep., National Bureau of economic research, 1991.

Gurney, K. R., J. Liang, R. Patarasuk, Y. Song, J. Huang, and G. Roest, The vulcan version 3.0 high-resolution fossil fuel co2 emissions for the united states, Journal of Geophysical Research: Atmospheres, 125, e2020JD032,974, 2020.

Gurney, K. R., J. Liang, G. Roest, Y. Song, K. Mueller, and T. Lauvaux, Underreporting of greenhouse gas emissions in us cities, Nature communications, 12, $1-7,2021$.

Gurney, K. R., et al., Climate change: Track urban emissions on a human scale, Nature News, 525, 179, 2015.

Jones, C., and D. M. Kammen, Spatial distribution of us household carbon footprints reveals suburbanization undermines greenhouse gas benefits of urban population density, Environmental science \&3 technology, 48, 895-902, 2014.

Katircioğlu, S., and S. Katircioğlu, Testing the role of urban development in the conventional environmental kuznets curve: evidence from turkey, Applied Economics Letters, 25, 741-746, 2018.

Kaya, Y., K. Yokobori, et al., Environment, energy, and economy: strategies for sustainability, United Nations University Press Tokyo, 1997.

Khoshnevis Yazdi, S., and B. Shakouri, The effect of renewable energy and urbanization on co2 emissions: A panel data, Energy Sources, Part B: Economics, Planning, and Policy, 13, 121-127, 2018.

Lauvaux, T., et al., Policy-relevant assessment of urban co2 emissions, Environmental Science \& Technology, 54, 10,237-10,245, 2020. 
Liddle, B., and S. Lung, Age-structure, urbanization, and climate change in developed countries: revisiting stirpat for disaggregated population and consumption-related environmental impacts, Population and Environment, 31, 317-343, 2010.

Little, W., R. McGivern, and N. Kerins, Introduction to Sociology-2nd Canadian Edition, BC Campus, 2016.

Luqman, M., P. Rayner, and K. Gurney, Combining measurements of built-up area, nighttime light, and travel time distance for detecting changes in urban boundaries: Introducing the BUNTUS algorithm, Remote Sensing, 11, 2019.

Marland, G., and R. M. Rotty, Carbon dioxide emissions from fossil fuels: a procedure for estimation and results for 1950-1982, Tellus B: Chemical and Physical Meteorology, 36, 232-261, 1984.

Martínez-Zarzoso, I., and A. Maruotti, The impact of urbanization on co2 emissions: evidence from developing countries, Ecological Economics, 70, 1344$1353,2011$.

Nations, U., World Urbanization Prospects 2018 - Population Division - United Nations, 2018.

Oda, T., and S. Maksyutov, A very high-resolution $(1 \mathrm{~km} \times 1 \mathrm{~km})$ global fossil fuel co 2 emission inventory derived using a point source database and satellite observations of nighttime lights, Atmospheric Chemistry and Physics, 11, 543-556, 2011.

Oda, T., S. Maksyutov, and C. D. Elvidge, Disaggregation of national fossil fuel co2 emissions using a global power plant database and dmsp nightlight data, Proceedings of the Asia-Pacific Advanced Network, 30, 219-228, 2010.

Oda, T., S. Maksyutov, and R. J. Andres, The open-source data inventory for anthropogenic $\mathrm{CO}_{2}$, version 2016 (odiac2016): a global monthly fossil fuel $\mathrm{co}_{2}$ gridded emissions data product for tracer transport simulations and surface flux inversions, Earth System Science Data, 10, 87-107, 2018.

Ouyang, X., and B. Lin, Carbon dioxide (co2) emissions during urbanization: a comparative study between china and japan, Journal of Cleaner Production, 143, 356-368, 2017.

Patarasuk, R., et al., Urban high-resolution fossil fuel CO 2 emissions quantification and exploration of emission drivers for potential policy applications, Urban ecosystems, 19, 1013-1039, 2016.

Raupach, M. R., G. Marland, P. Ciais, C. Le Quere, J. G. Canadell, G. Klepper, and C. B. Field, Global and regional drivers of accelerating $\mathrm{CO} 2$ emissions, PNAS, 104, 10,288-10,293, 2007. 
Raupach, M. R., P. J. Rayner, and M. Paget, Regional variations in spatial structure of nightlights, population density and fossil-fuel $\mathrm{CO}_{2}$ emissions, Energy Policy, pp. 4756-64, 2010.

Rayner, P. J., M. R. Raupach, M. Paget, P. Peylin, and E. Koffi, A new global gridded dataset of $\mathrm{CO}_{2}$ emissions from fossil fuel combustion: 1: Methodology and evaluation, J. Geophys. Res., 115, D19,306, 2010.

Sadorsky, P., The effect of urbanization on co2 emissions in emerging economies, Energy Economics, 41, 147-153, 2014.

Salahuddin, M., M. I. Ali, N. Vink, and J. Gow, The effects of urbanization and globalization on co 2 emissions: evidence from the sub-saharan africa (ssa) countries, Environmental Science and Pollution Research, 26, 2699$2709,2019$.

Sargent, M., et al., Anthropogenic and biogenic $\mathrm{CO}_{2}$ fluxes in the Boston urban region, Proceedings of the National Academy of Sciences, 115, 7491-7496, 2018.

Seto, K. C., B. Güneralp, and L. R. Hutyra, Global forecasts of urban expansion to 2030 and direct impacts on biodiversity and carbon pools, Proceedings of the National Academy of Sciences, 109, 16,083-16,088, 2012.

Seto, K. C., S. J. Davis, R. B. Mitchell, E. C. Stokes, G. Unruh, and D. ÜrgeVorsatz, Carbon lock-in: types, causes, and policy implications, Annual Review of Environment and Resources, 41, 425-452, 2016.

Seto, K. C., et al., Human settlements, infrastructure and spatial planning, 2014.

Shahbaz, M., N. Loganathan, A. T. Muzaffar, K. Ahmed, and M. A. Jabran, How urbanization affects $\mathrm{CO} 2$ emissions in Malaysia? The application of STIRPAT model, Renewable and Sustainable Energy Reviews, 57, 83-93, 2016.

Stern, D. I., The environmental kuznets curve after 25 years, Journal of Bioeconomics, 19, 7-28, 2017.

Thompson, J., et al., A global analysis of urban design types and road transport injury: an image processing study, The Lancet Planetary Health, 4, e32-e42, 2020 .

Turnbull, J., C. Sweeney, A. Karion, T. Newberger, S. Lehman, and P. Tans, Toward quantification and source sector identification of fossil fuel CO2 emissions from an urban area: results from the INFLUX experiment, $J$ Geophys Res Atmos, 120, 292-312, 2015, zSCC: 0000132.

Uchiyama, K., Environmental Kuznets Curve Hypothesis and Carbon Dioxide Emissions, SpringerBriefs in Economics, Springer Japan, Tokyo, 2016. 
Wang, C., J. Lin, W. Cai, and Z. Zhang, Policies and practices of low carbon city development in china, Energy \& Environment, 24, 1347-1372, 2013.

Wang, R., et al., High resolution mapping of combustion processes and implications for $\mathrm{CO}_{2}$ emissions, Atmospheric Chemistry and Physics Discussions, 12, 21,211-21,239, 2012.

Ziskin, D., K. Baugh, F. C. Hsu, T. Ghosh, and C. Elvidge, Methods used for the 2006 radiance lights, Proceedings of the Asia-Pacific Advanced Network, 30, 131-142, 2010. 